\title{
EDITORIAL
}

\section{Endocrine therapy: defining the path of least resistance}

\author{
Andrew Stone ${ }^{1}$ and Elizabeth A Musgrove ${ }^{2^{*}}$ \\ See related research by Beelen et al. http://breast-cancer-research.com/content/16/1/R6, http://breast-cancer-research.com/content/16/1/R13, \\ and by Lin et al., http://breast-cancer-research.com/content/15/6/R119
}

\begin{abstract}
One of the best-characterized oncogenic mechanisms in breast cancer is the aberrant activation of phosphatidylinositol-3-kinase, protein kinase $B$, and mammalian target of rapamycin signaling. In both endocrine-resistant disease and breast cancer stem cells, this is commonly caused by specific genetic lesions or amplification of key pathway components or both. These observations have generated two interesting hypotheses. Firstly, do these genetic anomalies provide clinically significant biomarkers predictive of endocrine resistance? Secondly, do tamoxifen-resistant breast cancer cells emerge from a stem-like cell population? New studies, published in Breast Cancer Research, raise the possibility that these hypotheses are intrinsically linked.
\end{abstract}

In experimental models of estrogen receptor (ER)-positive breast cancer, the hyperactivation of phosphatidylinositol-3kinase (PI3K), protein kinase B (AKT), and mammalian target of rapamycin (mTOR) can impede the inhibitory effect of endocrine therapy. This hyperactivation can be caused by augmented growth factor signaling, inactivation of PI3K inhibitors such as phosphatase and tensin homologue, and mutation and/or amplification of PI3K subunits and activators. Although these aberrations are frequently observed in human breast cancer, their clinical significance in endocrine-resistant disease remains controversial. Recent studies by Beelen and colleagues [1,2] and Lin and colleagues [3] in Breast Cancer Research raise the possibility that heterogeneity between different breast cancer cell populations may contribute to divergent findings.

\footnotetext{
* Correspondence: liz.musgrove@glasgow.ac.uk

${ }^{2}$ Wolfson Wohl Cancer Research Centre, University of Glasgow, Garscube Estate, Switchback Road, Glasgow, Bearsden G61 1QH, Scotland Full list of author information is available at the end of the article
}

Breast cancer stem cells (BCSCs) commonly harbor gainof-function mutations in key components of the PI3K/AKT/ mTOR signaling pathway $[4,5]$. For example, mutations in PIK3CA, a gene encoding a catalytic subunit of PI3K, were recently reported to be present in 8 out of 11 BCSC populations extracted from breast cancer specimens but absent in normal mammary stem cells [4]. It is thought that such attributes facilitate BCSC characteristics such as drug resistance and tumor progression [5]. A growing body of evidence suggests that endocrine-resistant breast cancer cells may be derived from a stem-like cell population $[3,6]$. By interrogating the genetic and epigenetic profiles of multiple tamoxifen-resistant cell lines, Lin and colleagues [3] determined that both intrinsic and acquired resistance were strongly associated with the deregulation of genes related to pluripotency and differentiation, including sexdetermining region Y-box, E2F transcription factor, and retinoblastoma gene product family pocket proteins. This suggests that resistant cells could emerge from discrete populations of stem-like breast cancer cells. Because as few as 100 BCSCs were able to form tumors in mice, whereas tens of thousands of cells with alternative phenotypes failed to form tumors [7], it is apparent that endocrine-resistant BCSCs may represent a very small needle in a very large haystack. It is therefore questionable whether molecular biomarkers associated with this cell phenotype could be readily detectable in primary disease for diagnostic purposes.

Much controversy surrounds the clinical significance of PI3K/AKT/mTOR-associated biomarkers in breast cancer. Some reports, including that of Beelen and colleagues [2], suggest that PIK3CA mutation is associated with a longer disease-free survival, lower tumor grade, and increased ER expression [2,8,9], whereas others report an association with poor survival rates [10] (recently reviewed in [11]). Importantly, unlike other investigators, Beelen and colleagues [2] were able to examine whether these mutations were specifically associated with response to tamoxifen but did 
not observe a statistically significant interaction between tamoxifen treatment and PI3KA mutation. It would be interesting, based on the results of Lin and colleagues [3], to determine whether the same was true if PI3KA mutation rates were measured in BCSCs derived from the clinical trial cohorts used by Beelen and colleagues, although this is unlikely to be practicable.

Why would a PIK3CA mutation be predictive in some breast cancer cell types but not others? Stem cells have a greater propensity to accumulate genetic and epigenetic modifications in order to acquire a survival advantage when under selection pressure [12]. This phenomenon is further evidenced by the demonstration that emergent 'stem-like' resistant populations featured methylomic modifications to gene promoter regions associated with reduced expression of genes that conferred survival [3]. With the emergence of epigenetic biomarkers across multiple aspects of breast cancer research, this highlights a potential use for DNA methylation biomarkers as predictors of tamoxifen response with prospective application in neo-adjuvant studies, as discussed previously [13].

Biomarkers downstream of PI3K/AKT/mTOR signaling may reflect pathway activation more accurately than activating mutations, since the effects of active signaling will be amplified across the entire tumor cell population through paracrine growth factor receptor pathways. In agreement with this idea, Beelen and colleagues [1] demonstrated that p-p70S6K, a phosphorylation target of mTOR, was predictive of tamoxifen resistance in post-menopausal patients with breast cancer but was associated with favorable prognosis in patients from the same clinical trial who did not receive tamoxifen. One could perhaps hypothesize that there exists a mechanism by which residual ER signaling limits the expansion of a BCSC population, similar to that previously shown to regulate neural stem cells [14]. In patients who received tamoxifen, inhibiting such regulation, or indeed the acquired genetic and epigenetic changes that are accumulated by residual breast cancer cells, could then positively select for a more aggressive cell phenotype, as previously suggested in experimental models $[3,13]$. Irrespective of the mechanistic basis for the predictive power of p-p70S6K, as suggested by Beelen and colleagues, p-p70S6K may provide a useful companion biomarker for the mTOR inhibitor, everolimus, which has recently been approved in Europe and the US in combination with endocrine therapy for the treatment of post-menopausal women with endocrine-resistant disease [15].

Although our understanding of the origins of endocrineresistant breast cancer is constantly evolving, it is obvious that the mechanisms that determine resistance are diverse, complex, and dynamic. Endocrine-resistant disease still represents one of the most challenging obstacles in breast cancer treatment. The appropriate use of PI3K/AKT/ mTOR signaling pathway inhibitors remains to be refined in endocrine resistance; however, clinical trials suggest that their clinical impact will be considerable. To maximize their therapeutic potential, it is critical that companion biomarkers of response be further characterized.

\section{Abbreviations}

AKT: Protein kinase B; BCSC: Breast cancer stem cell; ER: Estrogen receptor; mTOR: mammalian target of rapamycin; PI3K: Phosphatidylinositol-3-kinase; PIK3CA: Phosphatidylinositol-4,5-bisphosphate 3-kinase, catalytic subunit alpha; p-p70S6K: Phosphorylated p7056 kinase.

\section{Competing interests}

The authors declare that they have no competing interests.

\section{Acknowledgments}

AS is supported by the National Breast Cancer Foundation, Australia.

\section{Author details}

${ }^{1}$ Cancer Epigenetics Program, Garvan Institute of Medical Research, 384 Victoria Street, Darlinghurst, Sydney 2010 NSW, Australia. ${ }^{2}$ Wolfson Wohl Cancer Research Centre, University of Glasgow, Garscube Estate, Switchback Road, Glasgow, Bearsden G61 1QH, Scotland.

Published: 22 May 2014

\section{References}

1. Beelen K, Opdam M, Severson TM, Koornstra RH, Vincent AD, Wesseling J, Muris JJ, Berns EM, Vermorken JB, van Diest PJ, Linn SC: Phosphorylated p-70S6K predicts tamoxifen resistance in postmenopausal breast cancer patients randomized between adjuvant tamoxifen versus no systemic treatment Breast Cancer Res 2014, 16:R6.

2. Beelen $K$, Opdam M, Severson TM, Koornstra RH, Vincent AD, Wesseling J, Muris J, Berns EM, Vermorken JB, van Diest PJ, Linn SC: PIK3CA mutations, phosphatase and tensin homolog, human epidermal growth factor receptor 2 , and insulin-like growth factor 1 receptor and adjuvant tamoxifen resistance in postmenopausal breast cancer patients. Breast Cancer Res 2014, 16:R13.

3. Lin X, Li J, Yin G, Zhao Q, Elias D, Lykkesfeldt AE, Stenvang J, Brünner N, Wang J, Yang $H$, Bolund L, Ditzel HJ: Integrative analyses of gene expression and DNA methylation profiles in breast cancer cell line models of tamoxifen-resistance indicate a potential role of cells with stem-like properties. Breast Cancer Res 2013, 15:R119.

4. Pommier SJ, Hernandez A, Han E, Massimino K, Muller P, Diggs B, Chamberlain E, Murphy J, Hansen J, Naik A, Vetto J, Pommier RF: Fresh surgical specimens yield breast stem/progenitor cells and reveal their oncogenic abnormalities. Ann Surg Oncol 2012, 19:527-535.

5. Donovan CA, Pommier RF, Schillace R, O'Neill S, Muller P, Alabran JL, Hansen JE, Murphy JA, Naik AM, Vetto JT, Pommier SJ: Correlation of breast cancer axillary lymph node metastases with stem cell mutations. JAMA Surg 2013, 148:873-878

6. O'Brien CS, Farnie G, Howell SJ, Clarke RB: Breast cancer stem cells and their role in resistance to endocrine therapy. Horm Cancer 2011, 2:91-103.

7. Al-Hajj M, Wicha MS, Benito-Hernandez A, Morrison SJ, Clarke MF: Prospective identification of tumorigenic breast cancer cells. Proc Natl Acad Sci U S A 2003, 100:3983-3988.

8. Kalinsky K, Jacks LM, Heguy A, Patil S, Drobnjak M, Bhanot UK, Hedvat CV, Traina TA, Solit D, Gerald W, Moynahan ME: PIK3CA mutation associates with improved outcome in breast cancer. Clin Cancer Res 2009, 15:5049-5059.

9. Perez-Tenorio G, Alkhori L, Olsson B, Waltersson MA, Nordenskjold B, Rutqvist LE, Skoog L, Stal O: PIK3CA mutations and PTEN loss correlate with similar prognostic factors and are not mutually exclusive in breast cancer. Clin Cancer Res 2007, 13:3577-3584

10. Li SY, Rong M, Grieu F, lacopetta B: PIK3CA mutations in breast cancer are associated with poor outcome. Breast Cancer Res Treat 2006, 96:91-95.

11. Zardavas D, Phillips W, Loi S: PIK3CA mutations in breast cancer: reconciling findings from preclinical and clinical data. Breast Cancer Res 2014, 16:201.

12. Dean M, Fojo T, Bates S: Tumour stem cells and drug resistance. Nat Rev Cancer 2005, 5:275-284 
13. Stone A, Valdes-Mora F, Clark SJ: Exploring and exploiting the aberrant DNA methylation profile of endocrine-resistant breast cancer. Epigenomics 2013, 5:595-598.

14. Brannvall K, Korhonen L, Lindholm D: Estrogen-receptor-dependent regulation of neural stem cell proliferation and differentiation. Mol Cell Neurosci 2002, 21:512-520.

15. Baselga J, Campone M, Piccart M, Burris HA 3rd, Rugo HS, Sahmoud T, Noguchi S, Gnant M, Pritchard KI, Lebrun F, Beck JT, Ito Y, Yardley D, Deleu I, Perez A,

Bachelot T, Vittori L, Xu Z, Mukhopadhyay P, Lebwohl D, Hortobagyi GN:

Everolimus in postmenopausal hormone-receptor-positive advanced breast cancer. N Engl J Med 2012, 366:520-529.

doi:10.1186/bcr3659

Cite this article as: Stone and Musgrove: Endocrine therapy: defining the path of least resistance. Breast Cancer Research 2014 16:101. 